\title{
Narrative and Descriptive Text Revising Strategies and Procedures
}

\author{
Annie Piolat \\ Jean Yves Roussey \\ Université de Provence, Aix en Provence, France
}

\begin{abstract}
Forty-eight children and forty-eight adults of contrasting degrees of expertise made a series of corrections in order to improve a text (narrative or description) in which three within-statement errors and three between-statement errors had been inserted. Subjects used a simplified word processor (SCRIPREV) which recorded all movements of linguistic units

The purpose of this research was to study revising strategies by examining the correction-sequencing procedures implemented by these subjects. The procedures, which were coded in the form of time series, were compared to the time series of model revising procedures (i.e. effective ones) representing three strategies based on certain predefined functional principles (linguistic level, execution order).

The adults used two of these strategies. the Simultaneous Strategy for the narrative, and the Local-then-Global Strategy for the description. The children used the Local-then-Global Strategy for the narrative, but did not use any identifiable procedure to revise the description, which they did not manage to totally improve in the expected manner.
\end{abstract}

The problem

Scardamalia and Bereiter (1985) assume that, in order to modify a text, writers must read it for evaluation (compare), discover a difference between what they produced and what they intended or were supposed to say (diagnose), and then make a correction (operate).

Many studies have stressed how complex this activity actually is, and have provided evidence of substantial functional variations that depend on the age and degree of expertise of the writers, or upon other contextual variables (task, text type, etc.). These variants have been qualified as strategic. In our review (Piolat \& Roussey, in press), the expression «revising strategy» refers essentially to two levels of the revising activity:

The experiment reported in this article was conducted at the Centre de Recherche en Psychologie Cognitive, a research unit affiliated with the Centre National de la Recherche Scientifique, France. 
1) the reviser's overall representation of what he/she is supposed to do and of the linguistic aspects he/she must monitor (e.g. Bartlett, 1982; Collier, 1983; Daiute, 1989; Flower, Hayes, Carey, Schriver, \& Stratman, 1986; Kurth, 1987; Matsuhashi \& Gordon, 1985; McCormick Calkins, 1980);

2) the execution of the revising, viewed either as the punctual solving of a given problem (e.g. Scardamalia \& Bereiter, 1985; Flower, Hayes, Carey, Schriver, \& Stratman, 1986) or as the step-by-step transformation of an entire text (Piolat, Roussey, \& Guercin, 1989).

\section{The strategies and cognitive processes of revision}

Among the various proposals made to define and study revising strategies, the one made by Hayes, Flower, Schriver, Stratman, and Carey (1987) is undeniably the most precise. These authors give a more complex description of the «reviewing» process, previously thought to be composed of only two sub-processes («evaluate» and «revise»; Flower \& Hayes, 1981), by breaking down the process into four components and by further specifying the kind of knowledge the revising activity involves and generates. They grant a more important role to the reviser's selection of what knowledge to apply and what strategic choices to make as he/she

a) defines the task,

b) evaluates the text and defines the encountered problem,

c) selects a strategy involving either going back to the preceding processes or going on to modify the text, and

d) modifies the text either by revising it or rewriting it.

From a functional standpoint, the above sub-processes of revision are organized hierarchically. Each of the four steps required to make a correction is necessarily subordinate to the preceding one. The reviser can nevertheless decide not to go on to the next step, and restart the sequence at any one of the higher-order sub-processes. This process-sequencing flexibility accounts for the functional variants so fully described by Hayes et al. (1987). We have briefly summarized them below, while mentioning the choices writers can make as they first define the task and then select a revising strategy.

In order to revise, writers must have, and if not build, a representation of what they consider to be involved in evaluating and improving a text. They must plan what they are going to do by specifying:

- The goals to be reached (for instance, revise to make the text clearer).

- The characteristics of the text to be examined (for instance, revise the local or global aspects of the text).

- The means that can be used to reach the defined goals (for instance, correct the text several times in succession).

Hayes et al. (1987) attribute a clearly metacognitive role to the notion of task definition. Indeed, this definition serves as the control manager for the sequencing of complex subprocesses by setting the goals, constraints, and criteria required to guide the entire revising activity. These authors make an inventory of the various «definitions of the task» that revisers of differing degrees of expertise can verbalize, and thus ascertain that experts have more meta-knowledge and knowledge likely to promote the setting of objectives like ((check for correct meaning, text length, and text type)), or «check the number, density, and complexity of the problems and errors in the to-be-improved text», etc. The scope of experts' processing unit is the entire text, whereas that of novices is the sentence. At this point, Hayes et al. (ibid.) violate their own usage rule for the term «strategy > , reserved for the «selection» component (see below). They speak of a «single-sentence strategy $>$ (p. 217) and a « limited- 
scope strategy» (p. 217). Finally, in addition to being much more elaborate, the task definition of experts remains more flexible than that of novices throughout the correction making process; this flexibility allows for modifying the goals that guide the revising whenever necessary.

One of the four components of this model of revision is exclusively devoted to the selection of one of the five adequate strategies whenever a problem is detected or diagnosed. This

component is situated in the overall structure at the intersection between 〈comprehension-evaluation» and «production of a correction〉》. The choice to use one of these strategies

is triggered by different factors, since the problems to be solved in text revising are very diverse (Faigley \& Witte, 1981).

Three of the five strategies («revising process implementation strategies〉〉) involve returning to one of the higher-level processes to reprocess the problem encountered. They are:

- Ignore the problem, assessed to be of little importance or too difficult to solve.

- Delay solving the problem, since, for example, on the first pass through the text, it was not compatible with the goal set at task definition time.

- Search for more information in memory or in the text in order to better understand or define the problem.

The other two strategies («text modification strategies〉>) pertain to the production aspects of the model:

- Rewrite in order to conserve the idea, but not the text. Depending on the nature and degree of difficulty of the to-be-solved problem, the reviser can either make a new rough draft or paraphrase the text.

- Revise the text in order to conserve whatever can be saved. The various revisions are grouped into a problem-solution matrix also called the «means-ends» table (the ends concern both communicative goals and text organization levels: the means include various highly diverse operations such as insertion, deletion, moving, etc.).

The studies conducted by Hayes et al. (1987; correction of errors introduced in relatively long texts, and analysis of the verbal protocols produced by the revisers during the revision process) confirmed the fact that revisers do indeed implement the defined functional variants. Thus the authors were able to conclude that the functioning of expert and nonexpert revisers differs for each component of the model. To give an example, experts diagnose most problems and revise more often than they rewrite, while nonexperts do not.

This model succeeds in reducing the wide variety of functional variants to the activation of four processes and five strategies, while outlining the hierarchical nature of the reviser's functioning and the conditions under which strategical options are triggered. The validity of this model cannot be experimentally proven, since it remains both very broad in scope and highly complex in content. Revising strategies that are more local, but still compatible with this model, must therefore be developed.

\section{Strategies and correction-sequencing procedures}

In their model of the cognitive processes of revision, Hayes et al. (1987) specify the various steps and options taken by a reviser to make a correction, but they speak little about the order in which those corrections are made. They only hint at potential changes in the definition of the task as the revising is in progress, and simply mention that successive passes through the text are necessary for transforming the text to meet the preset goals.

But the revising activity most often consists of making a series of corrections of different types (each one enabling the reviser to attain only one of the task sub-goals). The reviser must therefore check the compatibility of each correction against a global text-improvement plan. Indeed, insofar as the different linguistic levels of a text (micro- and macrostructural) 
are interdependent, punctual modifications in the text may disrupt its overall structure, at the same time as more global corrections may make local readjustments necessary. To revise a text, the writer is thus confronted with the need to establish an order for making the necessary series of corrections, while simultaneously monitoring the coherency and cohesion of the text.

The on-line study of the progression of complex activities has become a crucial part of research in cognitive psychology, as strategic decisions may be made at every stage of the activity. The way in which a reviser, step by step, orders the corrections he or she decides to make is in our mind the result of a strategic decision, even if that decision involves proceeding ( (at random».

The purpose of this study is to specify what these options are: How do revisers of varying ages and levels of expertise string together a series of corrections in order to improve a text in which errors have been deliberately introduced? What are the functional principles underlying the way in which they proceed?

It appears relevant to us to distinguish between observable behavior and the processes which, on the basis of predictions, make that behavior possible. Only differences between procedures are observable. A given procedure results from the application of a strategy, which in turn is characterized by the hypothetical aspects of the subject's functioning that are to be established and validated. Before observing the way revisers actually operate, the strategies they could potentially use were expressed here in concrete form as model procedures.

By hypothesis in this study, the correction-sequencing strategies that allow revisers to transform a text as expected are based on the following functional principles:

- Correct errors in the text in their order of occurrence, starting at the beginning and going to the end of the text. The spatial organization of texts (obvious beginning and end, highly contingent linearization of words) can serve as a support for the thorough scanning, verification, and correction of all linguistic errors in the text.

- Either simultaneously or consecutively improve the within- and betweenstatement levels of the text. Given that the management of a series of problems pertaining to different linguistic levels may cause a cognitive overload, the reviser can either handle these two levels at the same time (simultaneous processing) or one after the other (consecutive processing).

- Make the corrections economically by moving as few linguistic items as possible.

By combining these principles, three theoretical correction-sequencing strategies for obtaining the expected final text were defined:

1. Simultaneous Strategy (S.S.)

- A single, in-order pass through the text.

- Simultaneous monitoring of all linguistic levels.

2. Local-then-Global Strategy (L.G.S.)

- At least two in-order passes through the text.

- Monitoring of the surface (within-statement) level first, then the deep (between-statement) level.

3. Global-then-Local Strategy (G.L.S.)

- At least two in-order passes through the text.

- Monitoring of the deep (between-statement) level first, then the surface (within-statement) level.

These theoretical correction-sequencing strategies are based on the assumption that a reviser is an ideal executor who: 
- has constructed a representation of the to-be-attained product that conforms to the product expected by the researcher;

- has properly diagnosed all of the linguistic problems;

- corrects in an economical manner.

Natural situations of text modification during composition are obviously more complex than the one imposed on the revisers here. Nevertheless, if we find out that the theoretical strategies were in fact employed, it will be possible to deduce that the functional principles upon which they are based are essential to the overall revision of texts.

\section{Method}

Forty-eight children whose mean age was 10.6 years (ranging from 9 years and 11 months to 12 years and 1 month) and forty-eight adults, classified as expert or nonexpert on the basis of their degree of expertise in writing, revised one of two experimental texts. The experts and nonexperts in each group were not comparable, since classification was not based on the same criteria in each case. The expert/nonexpert distinction was designed simply to take into account prior experimental results providing evidence of significant variations in performance within same age groups (Fayol \& Gombert, 1987). The children's degree of expertise was assessed by their teacher (each child in the class was labelled as expert or nonexpert and then names were drawn in each of the two groups). The adult experts were high school graduates who had frequent contact with writing; the nonexperts had not had much education, and did not work in a profession that involved writing on a daily basis.

The texts (a narrative and a description) each consisted of eight statements, six of which had been modified (errors were inserted) so as to encourage the subjects to make three local corrections (within-statement) in order to reestablish proper syntax and semantics (insert, delete, move nouns) and three global corrections (between-statement) in order to reestablish text coherency (insert, delete, move statements; see Appendix).

The computer-assisted revising system (SCRIPREV) required the subjects to modify the text by using only the verbal material displayed on the screen. This system operates like a highly simplified word processor. The reviser used an optical pencil to point on the screen to the linguistic segment (from 1 to $\mathrm{N}$ words) he or she wished to move, and to the location he or she wished to move it to (in the text or outside the text). After each move, the computer justified the text and recorded all manipulations.

To determine what revising strategy was used by the subjects, each of the predefined model procedures was coded in time series format. A time series is a set of data organized into a sequence of temporal instants. Two events were recorded at each instant: the exact identity of the linguistic item involved in the manipulation, and the location in the text where the subject was revising.

Whenever a subject was found to have revised the text in the expected manner ( 52 subjects out of 96; see Roussey, Piolat, \& Guercin, 1990), his/her procedure (actual times series) was compared to the model time series by calculating the distance between structures according to a method developed by Guercin (1986) and Guercin, Roussey, and Piolat (1990). The strategy corresponding to the model time series closest to the actual time series was attributed to that subject. Only a small number of subjects, mostly experts, could be attributed a strategy ( 28 out of the 52 subjects who revised the text as expected).

\section{Results}

The actual procedures varied by age and type of text. 
Table 1

Distribution of subjects according to wether or not they improved the text and/or followed one of the model procedures, by age, text type, and degree of expertise.

\begin{tabular}{|c|c|c|c|c|c|c|c|c|c|}
\hline \multirow[b]{3}{*}{ Subjects } & \multirow[b]{3}{*}{ Text type } & \multirow[b]{3}{*}{ Expertise } & \multicolumn{5}{|c|}{ Improved text } & \multirow{3}{*}{$\begin{array}{l}\text { Incomplete } \\
\text { text }\end{array}$} & \multirow[b]{3}{*}{$N$} \\
\hline & & & \multicolumn{4}{|c|}{ Observed strategy } & \multirow{2}{*}{$\begin{array}{l}\text { No observed } \\
\text { strategy }\end{array}$} & & \\
\hline & & & S.S & L.G.S & J.L.S. & Total & & & \\
\hline \multirow{3}{*}{ Adults } & Narrative & $\begin{array}{c}\mathbf{E}- \\
\mathbf{E}+ \\
\mathbf{E}-\stackrel{\&}{\mathrm{E}+}\end{array}$ & $\begin{array}{l}1 \\
7 \\
8\end{array}$ & $\begin{array}{l}2 \\
1 \\
3\end{array}$ & $\begin{array}{l}1 \\
0 \\
1\end{array}$ & $\begin{array}{r}4 \\
8 \\
12\end{array}$ & $\begin{array}{l}1 \\
2 \\
3\end{array}$ & $\begin{array}{l}7 \\
2 \\
9\end{array}$ & $\begin{array}{l}12 \\
12\end{array}$ \\
\hline & \multirow[t]{2}{*}{ Description } & $\begin{array}{c}E- \\
E+ \\
E-\stackrel{E}{E}+\end{array}$ & $\begin{array}{l}0 \\
2 \\
2\end{array}$ & $\begin{array}{l}2 \\
4 \\
6\end{array}$ & $\begin{array}{l}0 \\
1 \\
1\end{array}$ & $\begin{array}{l}2 \\
7 \\
9\end{array}$ & $\begin{array}{l}3 \\
5 \\
8\end{array}$ & $\begin{array}{l}7 \\
0 \\
7\end{array}$ & $\begin{array}{l}12 \\
12\end{array}$ \\
\hline & & Total & 10 & 9 & 2 & 21 & 11 & 16 & 48 \\
\hline \multirow{3}{*}{ Children } & Narrative & $\begin{array}{c}E- \\
E_{+}^{+} \\
E-\& E+\end{array}$ & $\begin{array}{l}1 \\
0 \\
1\end{array}$ & $\begin{array}{l}0 \\
4 \\
4\end{array}$ & $\begin{array}{l}0 \\
0 \\
0\end{array}$ & $\begin{array}{l}1 \\
4 \\
5\end{array}$ & $\begin{array}{l}0 \\
7 \\
7\end{array}$ & $\begin{array}{r}11 \\
1 \\
12\end{array}$ & $\begin{array}{l}12 \\
12\end{array}$ \\
\hline & Description & $\begin{array}{c}\text { E- } \\
\mathrm{E}+ \\
\mathrm{E}-\stackrel{\mathrm{E}}{\mathrm{E}+}\end{array}$ & $\begin{array}{l}0 \\
1 \\
1\end{array}$ & $\begin{array}{l}0 \\
1 \\
1\end{array}$ & $\begin{array}{l}0 \\
0 \\
0\end{array}$ & $\begin{array}{l}0 \\
2 \\
2\end{array}$ & $\begin{array}{l}2 \\
4 \\
6\end{array}$ & $\begin{array}{r}10 \\
6 \\
16\end{array}$ & $\begin{array}{l}12 \\
12\end{array}$ \\
\hline & & Total & 2 & 5 & 0 & 7 & 13 & 28 & 48 \\
\hline \multicolumn{3}{|c|}{ Adults and Children } & 12 & 14 & 2 & 28 & 24 & 44 & 96 \\
\hline
\end{tabular}

Note. $\mathbf{E}+=$ more expert; $\mathrm{E}-\mathbf{=}$ less expert

The global-then-local Strategy (G.L.S.) was not used.

For the narrative, the Simultaneous Strategy (S.S.) was most often used by adults, whereas the Local-then-Global Strategy (L.G.S) was used more by children. For the description, more adults used the Local-then-Global Strategy (L.G.S), while only two of the expert children used any one of the model strategies.

It looks as though adults revised by relying on their textual knowledge, proceeding step by step in a linear fashion in order to simultaneously find and solve all of the linguistic problems diagnosed in a single pass through the text. The Simultaneous Strategy (S.S.) may be particularly well suited to monitoring the highly restricted order of the statements in narrative texts, which adults master well. When confronted with a description, however, adults may have more difficulty predicting their final product at the beginning of task execution. Thus, although for some of the adults, a single pass through the text was sufficient, others required several in-order passes to arrive at the desired improvement. For both the narrative and the description, the adults did not find it useful to revise the overall structure of the text as long as the statements themselves were syntactically or semantically unacceptable.

The children (even the experts) were not able to reestablish the correct structure of the description, with which they appear to be unfamiliar. They essentially made local corrections (see Piolat, Roussey, \& Farioli, 1987). It was therefore not possible to attribute one of the theoretical strategies to these subjects. To improve the narrative, although children at this age have sufficient mastery of the narrative superstructure, even the experts were not 
able to process both linguistic levels at once. They revised the overall structure of the text after having done the necessary within-statement ((clean up».

These results are interpreted in another article (Roussey, Piolat, \& Guercin, 1990). The interpretation concerns three groups of revisers: those who managed to produce the expected text by employing one of the model strategies, those who proceeded in a different manner, and finally, those who were unable to produce the required revised text.

\section{Discussion}

Our goal here was to propose an initial account of the utility of the notion of revising strategy.

Our method of analysis of the step-by-step progression of the text revising activity enabled us to point out that certain model procedures were used especially by child experts, while others were implemented by adult experts. (The adults were able to simultaneously handle problems at two linguistic levels). However, the adults did not use the same strategy to revise the narrative and the description.

A parallel may be drawn between these findings and the proposals made by Hayes et al. (1987).

Accordingly, revisers who use a simultaneous processing strategy may have defined the task outright by assessing both the micro- and macro-linguistic levels of the text. Revisers using a consecutive processing strategy, on the other hand, may have had that same linguistic goal, but have decided to reach it via two consecutive passes through the text. Or, they may have had a more limited definition of the task at the onset, only later to discover as they revised at the local level that they needed to pass through the text a second time to improve the global level, thus changing their definition of the task (adaptive «flexibility»).

As with the description, the expert adults may, at task definition time, have decided to improve both linguistic levels but in a consecutive fashion in order to handle the more delicate revision of this more difficult type of text; or they may have modified their task definition, incomplete at first, since problems are more difficult to anticipate for this more complex text structure.

The main limitation of our approach is that in our definition of model revising procedures, only one final state of the text was considered (the state obtained when the expected corrections were made). This meant rejecting a relatively large number of subjects from our protocol analysis. However, the defined models did enable us to characterize the functioning of a third of all subjects, and over half of all experts.

Furthermore, the final state of the text could be obtained only by using the linguistic items displayed on the screen. In a spontaneous revising situation where the writer can insert new items, it would only be possible to predict the solution for problems involving «rules» or «maxims» (see Hayes et al., 1987). In this case, the problem definition would lead to diagnostics calling for modifications in the text to which anyone would agree. On the other hand, problems pertaining to «communicative intentions» can be solved in many different ways, all equally valid and thus unpredictable.

The main advantage of our approach lies in the fact that in this experimental situation, which is constraining for the revisers but highly controlled, it is possible to compare the procedures actually used to model procedures, while varying different factors (characteristics of the subjects, type of errors introduced in the texts, text difficulty, etc.). Several new research goals may now be set, particularly in the area of development (Fayol \& Gombert, 1987), such as:

- Determine whether the strategies employed can be ordered by difficulty (work load, simultaneous use of several knowledge bases, etc). 
- Define potential affiliations between strategies (in a developmental perspective aimed at teaching written composition).

- Find out whether certain strategies are better suited to certain text types (potential set of strategies constituting expertise).

By devising theoretical strategies, a priori, to describe the step-by-step execution of the writing task, and then expressing those strategies in concrete form as model procedures to be compared to the actual performance of revisers, we feel we have made the notion of revising strategy operational for future hypothetico-deductive research.

\section{References}

Bartlett, E. (1982). Learning to revise: Some component processes. In M. Nystrand (Ed.), What writers know. The language process and structure of written discourse, (pp. 345-364). New York: Academic Press.

Collier, R. M. (1983). The word processor and revision strategies. College Composition and Communication, $34,149-155$.

Daiute, C. (1989). Play as thought: Thinking strategies of young writers. Harvard Educational Review, 59, 1-23.

Faigley, L., \& Witte, S. (1981). Analyzing revision. College Composition and Communication, 32, 400-414.

Fayol, M., \& Gombert, J. E. (1987). Le retour de l'auteur sur son texte: Bilan provisoire des recherches psycholinguistiques. Repères, 73, 85-95.

Flower, L., \& Hayes, J. R. (1981). A Cognitive Process Theory of Writing. College Composition and Communication, $32,365-387$

Flower, L., Hayes, J. R., Carey, L., Schriver, K., \& Stratman, J. (1986). Detection, diagnosis, and the strategies of revision. College Composition and Communication, 37, 16-55.

Guercin, E (1986). Proposition de logiciel pour le traitement des chroniques. Congrès Annuel de la S.F.P. (section de Psychologie Expérimentale), Aix-En-Provence, 13-14 Mars.

Guercin, F., Roussey, J. Y., \& Piolat, A. (1990). Time series: A tool for analyzing complex cognitive activities. Application to the study of text revising strategies. CPC/European Bulletin of Cognitive Psychology, 1, 79-110.

Hayes, J. R., Flower, L. S., Schriver, K., Stratman, J., \& Carey, L. (1987). Cognitive processes in revision. In S. Rosenberg (Ed.), Reading, writing, and language learning Advances in applied psycholinguistics, Vol. II, (pp. 176-240). Cambridge: Cambridge University Press.

Kurth, R. J. (1987). Using word processing to enhance strategies during student writing activities. Educational Technology, January, $13-19$.

Mc Cormick Calkins, L. (1980). Notes and comments. Children's rewriting strategies. Research in the Teaching of English, 14, 331-341.

Matsuhashi, A., \& Gordon, E. (1985). Revision, addition, and the power of the unseen text. In S. W. Freedman (Ed.). The acquisition of written language : Response and revision, (pp. 226-249). Norwood, N.J.: Ablex.

Piolat, A., \& Roussey, J:Y. (in press). A propos de l'expression «stratégie de révision» de textes en psychologie cognitive. Textes en Main.

Piolat, A., Roussey, J.Y., \& Farioli, E (1987). Révision de texte par l'enfant et l'adulte en production assistée par ordinateur. Bulletin d A udiophonologie, 3, 733-748.

Piolat, A., Roussey, J.- Y, \& Guercin, E (1989). Text revising strategies. In P. Boscolo (Ed.), Writing: Trends in European Research, (pp. 12-20). Padova: U.P.S.E.L. Editore.

Roussey, J.-Y., Piolat, A., \& Guercin, F. (1990). Revising strategies for different text types. Language and Education, $4(1), 51-65$.

Scardamalia, M., \& Bereiter, C. (1985). Fostering the development of self-regulation in children's knowledge Processing. In S. F. Chipman, J. W. Segal \& R. Glaser (Eds.), Thinking and learning skills. Research and open questions, (pp. 563-577). Hillsdale, N.J.: L.E.A

\section{Appendix}

Narrative

Basic text

Dans un bassin deux dauphins commencent un numéro. Après quelques sauts ils se renvoient un ballon par dessus un filet. Soudain le ballon tombe en dehors du bassin. Cette maladresse 
va interrompre le spectacle. Mais une fille court après le ballon et l'envoie aux dauphins. Les dauphins récupèrent le ballon rejeté dans l'eau. Ainsi ils peuvent reprendre le numéro. Le spectacle finit bien.

\section{Experimental text}

Dans un bassin deux dauphins commencent un numéro. Après quelques sauts ils se renvoient un filet par dessus un ballon. La mouette a un petit bec jaune. Les dauphins récupèrent le ballon rejeté dans l'eau. Cette maladresse va interrompre le spectacle nageoire. Mais une court après le ballon et l'envoie aux dauphins. Soudain le ballon tombe en dehors du bassin. Le spectacle finit bien.

fille / robe écossaise / Ainsi ils peuvent reprendre le numéro /

Description

Basic text

Le dauphin est un mammifère. marin. Son corps allongé et gris ressemble à celui d'un requin. Sa tête se prolonge en un grand museau appelé rostre. Sa bouche a une centaine de dents pointues. Le dauphin intelligent apprend à jouer avec l'homme. Il saisit un bâton que lui tend le dresseur. Il saute très haut à travers un cerceau. Il pousse des ballons dans un filet.

\section{Experimental text}

Le dauphin est un mammifère marin. Son requin allongé et gris ressemble à celui d'un corps. La mouette nettoie ses plumes. Il saisit un bâton que lui tend le dresseur. Sa bouche a une centaine de dents pointues. Le dauphin intelligent apprend à jouer avec l'homme nageoire. Sa tête se prolonge en un grand museau appelé rostre. Il pousse des ballons dans un filet.

dents / robe écossaise / Il saute très haut à travers un cerceau /

Key words Procedure, Revision, Strategy, Time series, Text type.

Annie Piolat. PsyCLE., Université de Provence, 29 Avenue Robert Schuman, 13621 Aix-en-Provence, Cedex 1, France.

Current theme of research:

Control of text production; Text revising processes

Most relevant publications in the field of Educational Psychology:

Guercin, R, Roussey, J.-Y., \& Piolat, A. (1990). Time series: A tool for analizing complex cognitive activities. Application to the study of text revising strategies. CPCI European Bulletin of Cognitive Psychology, 1, 79-110.

Piolat, A., \& Roussey, J:Y. (in press). A propos de l'expression «stratégie de révision» de textes en psychologie cognitive. Textes en Main.

Roussey, J.-Y., Piolat, A., \& Guercin, F. (1990). Revising strategies for different text types. Language and Education, $4(1), 51-65$

Jean-Yves Roussey. PsyCLE, Université de Provence, 29 Avenue Robert Schuman, 13621 Aix-en-Provence, Cedex 1, France.

Current theme of research:

Control of text production, Text revising processes. 